\title{
Aspectos fitossociológicos da Comunidade de Plantas Daninhas na Cultura do Feijão sob Diferentes Sistemas de PREPARO do SOlO ${ }^{1}$
}

\author{
Phytosociological Aspects of the Weed Community in Bean Crop under Different Soil \\ Tillage Systems
}
SILVA, A.A. ${ }^{2}$, SILVA, C.S.W. ${ }^{3}$, SOUZA, C.M. ${ }^{2}$, SOUZA, B.A. ${ }^{4}$, FAGUNDES, J.L. ${ }^{4}$, FALLEIRO, R.M. ${ }^{4}$ e SEDIYAMA, C.S. ${ }^{2}$

\begin{abstract}
RESUMO - Avaliou-se, neste trabalho, os efeitos de sistemas de preparo do solo: [(plantio direto (PD), arado de discos $(\mathrm{AD})$, arado de aivecas (AA), grade aradora (GA), grade aradora+arado de discos $(G A+A D)$ e grade aradora+arado de aivecas $(G A+A A)]$ sobre a comunidade de plantas daninhas da cultura do feijão. Este experimento foi desenvolvido em área onde os diferentes sistemas de preparo do solo estavam sendo avaliados desde 1985. Todavia, os resultados aqui apresentados são referentes apenas à safra 2000/2001. Neste ensaio, as parcelas foram subdivididas pela aplicação ou não de herbicidas em pósemergência. As plantas daninhas presentes na área experimental foram separadas por espécie, classificadas, secadas e pesadas, sendo analisadas segundo a sua importância relativa dentro da comunidade, através dos índices fitossociológicos de densidade, freqüência e dominância. A aplicação de herbicidas em pós-emergência diminuiu a biomassa total das plantas daninhas, e esse efeito foi independente do sistema de preparo. Os sistemas de preparo do solo e a aplicação de herbicida em pós-emergência alteraram a importância relativa das plantas daninhas dentro da comunidade. As espécies que apresentaram maior importância foram Cyperus rotundus, nos tratamentos com preparo convencional do solo, e Galinsoga parviflora, no plantio direto.
\end{abstract}

Palavras-chave: plantio direto, plantio convencional, importância relativa, índices fitossociológicos.

ABSTRACT - Tillage systems change the floral composition of a weed community. The changes can be either a simple fluctuation in plant population or the establishment of a permanent new weed community, affecting competition, management and control. The aim of this work was to evaluate the effects of tillage systems on the weed community in bean crop in areas where different tillage systems were being applied since 1985. The experimental soil was cultivated with annual cultures and submitted to six tillage systems: no-tillage (PD), moilboard plow (AD), plow of disc (AA), heavy bars (GA), heavy bars + moilboard plow $(G A+A D)$ and heavy bars + plow of disc $(G A+A A)$. The results discussed in this work are related to the 2001 winter-spring crop season only. The plots were divided in two sub-plots, and submitted or not to treatment with post-emergence herbicide, resulting in a complete randomized block design with four replications. The weeds were grouped by species, classified, dried and weighed. Total dry biomass and density of the weeds were submitted to the Tukey test. The weed species were analyzed according to their relative importance in the weed community, taking into account the phytosociological indices of density, frequency and dominance. Herbicide application in post-emergence reduced the total biomass of the weeds. Herbicide effect was independent of the soil tillage systems used. The soil tillage systems and herbicide application in post-emergence modified the relative importance of the weed species in the community. The species showing higher relative importance were Cyperus rotundus, in the treatments under conventional soil preparation, and Galinsoga parviflora, under no-tillage, mainly where the herbicide was applied in post-emergence.

Key words: no-tillage, tillage, relative importance, phytosociological indices.

Recebido para publicação em 22.9.2003 e na forma revisada em 21.4.2005.

Prof. do Dep. de Fitotecnia da Universidade Federal de Viçosa - UFV, 36570-000 Viçosa-MG, < aasilva@ufv>; ${ }^{3}$ Mestrando em Fitotecnia - UFV, ${ }^{4}$ Doutorando em Fitotecnia - UFV. 


\section{INTRODUÇÃO}

O preparo periódico do solo promove o controle de plantas daninhas, o qual se deve ao efeito mecânico de quebra, ao arranque e à exposição das estruturas das plantas à secagem pelo sol, promovendo a redução do banco de sementes do solo (Radosevich et al., 1996). Entretanto, o revolvimento contínuo do solo pode promover a disseminação de algumas espécies de plantas que se propagam vegetativamente, proporcionando altas infestações (Jakelaitis et al., 2003). O efeito de diferentes implementos no preparo sobre a comunidade de plantas daninhas depende da intensidade de revolvimento do solo e da profundidade de enterrio, tanto da palhada como das plantas daninhas e suas sementes. Segundo Radosevich et al. (1996), a intensidade de revolvimento é maior nos sistemas que utilizam a seguinte ordem de preparo do solo: grade aradora + arado de aiveca $(\mathrm{GA}+\mathrm{AA})>$ arado de aiveca $(\mathrm{AA})>$ grade aradora + arado de disco $(G A+A D)>$ arado de disco $(A D)>$ grade aradora (GA). No entanto, a utilização do sistema de plantio direto reduz drasticamente o revolvimento mecânico do solo e mantém os resíduos culturais na sua superficie. Nesse caso, o controle de plantas daninhas deve ser feito com herbicidas dessecantes (Ferreira et al., 1998).

A não-incorporação dos materiais vegetais presentes na superficie do solo provoca alterações na dinâmica do banco de sementes das plantas daninhas, influenciando a quebra da dormência, a germinação e a ação dos microrganismos. Outro aspecto importante da palhada é a possibilidade de liberação de substâncias alelopáticas, que pode prejudicar ou favorecer a germinação e o desenvolvimento das plantas daninhas (Theisen \& Vidal, 1999).

Os efeitos diferenciados dos sistemas de preparo do solo sobre as plantas daninhas podem modificar a composição botânica da comunidade (Duarte \& Deuber, 1999; Pereira et al., 2000; Jakelaitis et al., 2003). Essas modificações podem ser simples flutuações populacionais associadas a alterações temporárias ou podem ser definitivas, apresentando comportamento semelhante ao fenômeno da sucessão ecológica. A evolução florística da comunidade ocorre de acordo com a intensidade, a regularidade e o tempo de utilização do sistema (Zanin et al., 1997). Dependendo da intensidade, essas alterações podem afetar o manejo, o controle e a competição exercida por essa comunidade com a cultura (Ghersa et al., 2000).

Objetivou-se neste trabalho avaliar as alterações provocadas por diferentes sistemas de preparo do solo sobre a comunidade de plantas daninhas na cultura do feijão, em uma área submetida por 15 anos consecutivos a seis diferentes sistemas de preparo do solo.

\section{MATERIAL E MÉTODOS}

O trabalho foi desenvolvido no municipio de Coimbra-MG, em região de clima classificado como tropical de altitude, com precipitação média anual de 1.300 a $1.400 \mathrm{~mm}$, concentrada, principalmente, nos meses de outubro a março, e temperatura média anual de $19{ }^{\circ} \mathrm{C}$. O experimento vem sendo conduzido desde a safra 1985/86, em um Argissolo Vermelho-Amarelo câmbico, com declividade média de $5 \%$.

O delineamento experimental utilizado foi o de blocos completos casualizados, com seis tratamentos e quatro repetições. Cada parcela ocupou área de $112 \mathrm{~m}^{2}$ (14 x $\left.8 \mathrm{~m}\right)$, separadas entre si por ruas de $5 \mathrm{~m}$, e os blocos, por ruas de $3 \mathrm{~m}$. Os tratamentos consistiram dos seguintes sistemas de preparo: plantio direto (PD), arado de discos (AD), arado de aivecas (AA), grade aradora (GA), grade aradora+arado de discos $(\mathrm{GA}+\mathrm{AD})$ e grade aradora+arado de aivecas $(\mathrm{GA}+\mathrm{AA})$. O controle de plantas daninhas durante todo o experimento foi realizado preferencialmente com herbicidas. Nas operações de dessecação das plantas daninhas, realizadas apenas no tratamento $\mathrm{PD}$, foram utilizadas misturas dos herbicidas glyphosate e 2,4-D; após 1999, passou a ser utilizado apenas o glyphosate. Os herbicidas aplicados em pós-emergência variaram de acordo com a cultura, sendo o atrazine o mais empregado.

Para a realização deste ensaio (safra $2001 / 2002)$, cada parcela foi dividida em duas subparcelas: com a aplicação de herbicidas em pós-emergência e sem a aplicação de herbicidas, formando um delineamento em blocos completos casualizados, com parcelas subdivididas. As avaliações correspondem à safra de feijão inverno-primavera 2001. No dia 20/7/2001 foi realizada a dessecação 
das plantas daninhas com glyphosate $\left(1.080,0 \mathrm{~g} \mathrm{ha}^{-1}\right)$, no tratamento PD. No dia 25/7/2001 foi realizado o preparo do solo nos tratamentos convencionais. A operação de semeadura do feijão (var. Meia-Noite) foi realizada em 30/7/2001 com semeadora/adubadora própria para plantio direto, com cinco linhas espaçadas de $50 \mathrm{~cm}$, reguladas para depositar 15 sementes por metro linear (300.000 sementes ha-1). Na adubação de semeadura foram utilizados $175 \mathrm{~kg} \mathrm{ha}^{-1}$ de N-P-K, fórmula 8-28-16. Imediatamente após a semeadura foi realizada a primeira irrigação, aplicando-se uma lâmina de água de $30 \mathrm{~mm}$, que foi repetida uma vez por semana, até setembro, quando reiniciaram as chuvas. A adubação de cobertura foi feita em 20/8/2001, na dose de $20 \mathrm{~kg} \mathrm{ha}^{-1}$ de $\mathrm{N}$ na forma de uréia.

Nas subparcelas com controle de plantas daninhas em pós-emergência, foi aplicada a mistura herbicida fluazifop-p-butil + fomesafen $\left(160+200 \mathrm{~g} \mathrm{ha}^{-1}\right)$, aos 32 dias após a semeadura (DAS).

Aos 99 DAS foi realizada a amostragem da comunidade de plantas daninhas, utilizandose um quadrado de $100 \times 100 \mathrm{~cm}$, lançado duas vezes ao acaso em cada subparcela. Todas as plantas que se encontravam dentro da área do quadrado foram retiradas, acondicionadas em sacos plásticos e armazenadas em câmara fria. Posteriormente, essas amostras foram levadas para o laboratório, separadas e classificadas por espécie. As espécies presentes em cada amostra foram contadas, para determinação do número de indivíduos; e secadas separadamente em estufa de circulação forçada de ar a $72{ }^{\circ} \mathrm{C}$ por 72 horas e pesadas, para determinação da biomassa seca de cada espécie. As médias de biomassa seca e de densidade de indivíduos, obtidas por meio da soma de todas as espécies presentes em cada tratamento, foram comparadas pelo teste de Tukey a $5 \%$ de probabilidade. Os dados relativos a cada espécie, em cada amostra, foram usados para determinação dos índices fitossociológicos das espécies, por meio da densidade relativa - DeR(\%), freqüência absoluta - FA(\%), freqüência relativa - $\mathrm{FR}(\%)$, dominância relativa - DoR(\%), indice do valor de importância IVI e importância relativa - IR(\%), conforme proposto por Pitelli (2000).

\section{RESULTADOS E DISCUSSÃO}

A aplicação dos herbicidas diminuiu a biomassa seca da comunidade de plantas daninhas em todos os sistemas de preparo, mas não influenciou a densidade destas na área (Tabela 1). A não-diferença na densidade de plantas daninhas pode ser atribuída à reinfestação da área tratada antes da avaliação final de controle. Quando não foram aplicados herbicidas, o tratamento GA+AD apresentou acúmulo de biomassa seca superior ao de todos os demais tratamentos. Os efeitos de herbicidas na diminuição da infestação por plantas daninhas, em termos de biomassa, foram também verificados por Zanin et al. (1997), Pasqualetto (1999), Abdin et al. (2000) e Jakelaitis et al. (2003).

Observaram-se diferenças entre os índices fitossociológicos de densidade, biomassa e freqüência das plantas daninhas, dentro de cada tratamento (Tabela 2). Artemisia verlotorum e Digitaria sp. apresentaram valores de freqüência relativa (FR) elevados nos sistemas com preparo convencional do solo, em relação às suas respectivas densidade (DeR) e dominância relativa (DoR). No PD, os valores de DeR de Digitaria sp. foram superiores aos de FR e DoR. Esse resultado discorda dos obtidos por Zanin et al. (1997) com $D$. sanguinalis e por Pasqualetto (1999) com $D$. horizontalis, que constataram alta freqüência de plantas do gênero Digitaria em áreas sob $\mathrm{PD}$, principalmente quando cultivadas com milho. A baixa freqüência de Digitaria em PD, neste trabalho, pode ser atribuída ao periodo de condução da cultura (safra inverno-primavera). Ferreira et al. (1998) destacam que os plantios de inverno e outono, em regiões onde ocorrem baixas temperaturas durante o inverno, podem dificultar a germinação e o desenvolvimento de diversas plantas daninhas, em especial as do tipo $\mathrm{C}_{4}$. Entretanto, as espécies Brachiaria plantaginea e Zea mays, também do tipo $\mathrm{C}_{4}$, apresentaram elevada DoR nos tratamentos com preparo convencional do solo; nesta última, a DoR diminuiu conforme aumentou a intensidade e profundidade de revolvimento. Cyperus rotundus apresentou maiores valores de DeR e FR, em comparação com a DoR. Resultado semelhante foi obtido por Jakelaitis et al. (2003). Isso se deve à alta infestação promovida pela espécie nos tratamentos com preparo convencional, associada ao reduzido acúmulo de biomassa na parte aérea de cada indivíduo da espécie.

Planta Daninha, Viçosa-MG, v. 23, n. 1, p. 17-24, 2005 
As espécies da família Compositeae mostram comportamento diferenciado em relação aos sistemas de preparo. Bidens pilosa e, principalmente, Galinsoga parviflora apresentaram maior importância relativa (IR) no PD, enquanto Artemisia verlotorum apresentou maior IR nos tratamentos com preparo convencional do solo (Tabela 3). Em Bidens pilosa, a elevação da IR no tratamento PD foi devida, principalmente, aos valores mais elevados de DoR da espécie (Tabela 2) neste tratamento. O maior acúmulo de biomassa pode ser decorrente da redução da competição entre as espécies, uma vez que os valores de densidade e biomassa total da comunidade foram menores neste tratamento (Tabela 1). Galinsoga parviflora apresentou a maior IR dentro da comunidade no PD, devido aos elevados valores de DeR, FR e DoR da espécie neste tratamento (Tabela 2). Esta espécie possui sementes pequenas, o que pode dificultar a emergência das plântulas nos sistemas em que o preparo do solo atinge maiores profundidades, proporcionando menores densidades, como pode ser verificado na Tabela 2 , em que as densidades relativas da espécie seguiram a seguinte ordem: $\mathrm{PD}>\mathrm{GA}>\mathrm{AD}>\mathrm{GA}+\mathrm{AD}>\mathrm{AA}>\mathrm{GA}$ + AA.

Tabela 1 - Médias estimadas de biomassa seca e densidade de indivíduos da comunidade de plantas daninhas, em função dos diferentes sistemas de preparo do solo e da utilização de herbicidas em pós-emergência, após o cultivo do feijão. Coimbra-MG, 2001

\begin{tabular}{|c|c|c|c|c|c|c|c|}
\hline \multirow{2}{*}{ Controle $^{1 /}$} & \multicolumn{7}{|c|}{ Sistema de preparo do solo ${ }^{2 /}$} \\
\hline & PD & $\mathrm{AD}$ & AA & GA & $\mathrm{GA}+\mathrm{AD}$ & $\mathrm{GA}+\mathrm{AA}$ & Média \\
\hline & \multicolumn{7}{|c|}{ Biomassa seca $\left(\mathrm{g} \mathrm{m}^{-2}\right)$} \\
\hline $\mathrm{CC}$ & $2,36 \mathrm{~b}$ & $40,70 \mathrm{~b}$ & $25,15 b$ & $32,51 \mathrm{~b}$ & $36,05 b$ & $32,76 b$ & $28,26 \mathrm{~b}$ \\
\hline SC & $217,85 \mathrm{Ba}$ & $413,57 \mathrm{Ba}$ & $338,86 \mathrm{Ba}$ & $377,78 \mathrm{Ba}$ & $734,38 \mathrm{Aa}$ & $313,15 \mathrm{Ba}$ & $399,26 \mathrm{a}$ \\
\hline \multirow[t]{2}{*}{ Média } & $110,11 \mathrm{C}$ & $227,14 \mathrm{~B}$ & $182,00 \mathrm{BC}$ & $205,14 \mathrm{BC}$ & $385,20 \mathrm{~A}$ & $172,96 \mathrm{BC}$ & 213,76 \\
\hline & \multicolumn{7}{|c|}{ Densidade de indivíduos (plantas $\mathrm{m}^{-2}$ ) } \\
\hline $\mathrm{CC}$ & 4,50 & 446,25 & 185,75 & 383,25 & 374,00 & 365,00 & $293,13 b$ \\
\hline SC & 78,75 & 418,25 & 698,25 & 306,00 & 589,00 & 449,75 & $423,33 \mathrm{a}$ \\
\hline Média & 41,60 & 432,30 & 442,00 & 334,60 & 481,50 & 407,40 & 358,23 \\
\hline
\end{tabular}

Médias seguidas pela mesma letra não diferem estatisticamente entre si pelo teste de Tukey a $5 \%$ de probabilidade; letras maiúsculas comparam sistemas de preparo e letras minúsculas comparam o controle ou não em pós-emergência.

${ }^{1 /} \mathrm{CC}$ (com controle em pós-emergência) e SC (sem controle em pós-emergência).

${ }^{2}$ PD (plantio direto); AA (arado de aivecas); AD (arado de discos); GA (grade aradora).

Tabela 2 - Índices fitossociológicos (\%) de densidade (DeR), freqüência (FR) e dominância (DoR) das plantas daninhas presentes na cultura do feijão, em função dos diferentes sistemas de preparo do solo, sem a aplicação de herbicida em pósemergência. Coimbra-MG, novembro de 2001

\begin{tabular}{|c|c|c|c|c|c|c|c|c|c|c|c|c|c|c|c|c|c|c|}
\hline \multirow{3}{*}{ Espécie } & \multicolumn{18}{|c|}{ Sistema de preparo do solo ${ }^{1 /}$} \\
\hline & \multicolumn{3}{|c|}{ PD } & \multicolumn{3}{|c|}{$\mathrm{AD}$} & \multicolumn{3}{|c|}{ AA } & \multicolumn{3}{|c|}{ GA } & \multicolumn{3}{|c|}{$\mathrm{GA}+\mathrm{AD}$} & \multicolumn{3}{|c|}{$\mathrm{GA}+\mathrm{AA}$} \\
\hline & DeR & FR & DoR & DeR & FR & DoR & DeR & FR & DoR & DeR & FR & DoR & DeR & FR & DoR & DeR & FR & DoR \\
\hline Bidens pilosa & 7,94 & 14,00 & 14,58 & 4,90 & 13,33 & 9,94 & 2,11 & 10,61 & 10,89 & 4,17 & 13,56 & 5,06 & 2,67 & 10,77 & 4,84 & 2,67 & 10,29 & 9,19 \\
\hline Artemisia verlotorum & 0,32 & 2,00 & 0,57 & 2,03 & 8,33 & 0,57 & 6,84 & 10,61 & 5,61 & 0,90 & 6,78 & 0,08 & 0,30 & 4,62 & 0,08 & 1,67 & 7,35 & 0,49 \\
\hline Galinsoga parviflora & 57,14 & 16,00 & 28,66 & 12,67 & 11,67 & 15,47 & 5,41 & 10,61 & 12,33 & 21,32 & 13,56 & 14,05 & 5,69 & 12,31 & 3,02 & 3,17 & 10,29 & 2,91 \\
\hline${\text { Digitaria } \text { sp. }^{2}}^{2}$ & 10,16 & 4,00 & 1,24 & 1,14 & 8,33 & 0,71 & 1,29 & 10,61 & 2,61 & 2,45 & 6,78 & 0,39 & 2,25 & 10,77 & 1,54 & 0,94 & 10,29 & 1,13 \\
\hline Brachiaria plantaginea & 3,49 & 8,00 & 8,71 & 5,98 & 11,67 & 27,77 & 3,04 & 12,12 & 36,42 & 7,68 & 13,56 & 31,36 & 10,57 & 12,31 & 75,47 & 5,45 & 11,76 & 55,64 \\
\hline Zea mays & 2,22 & 6,00 & 41,02 & 1,26 & 8,33 & 21,81 & 0,36 & 7,58 & 13,26 & 1,55 & 13,56 & 16,05 & 0,21 & 6,15 & 5,79 & 0,50 & 5,88 & 6,40 \\
\hline Cyperus rotundus & 0,95 & 2,00 & 0,02 & 59,89 & 13,33 & 6,56 & 78,55 & 10,61 & 15,15 & 52,04 & 11,86 & 3,99 & 75,08 & 7,69 & 6,22 & 80,77 & 11,76 & 12,03 \\
\hline Ipomoea grandifolia & 2,22 & 10,00 & 0,22 & 0,54 & 6,67 & 0,30 & 0,39 & 7,58 & 0,16 & 0,49 & 6,78 & 0,20 & 0,47 & 7,69 & 0,15 & 0,61 & 7,35 & 0,23 \\
\hline Solanum americanum & 3,17 & 12,00 & 2,37 & 11,42 & 11,67 & 16,83 & 0,72 & 6,06 & 3,14 & 8,82 & 6,78 & 28,44 & 1,06 & 10,77 & 1,95 & 2,50 & 10,29 & 11,38 \\
\hline Richardia brasiliensis & 5,40 & 6,00 & 0,59 & 0,00 & 0,00 & 0,00 & 0,29 & 4,55 & 0,06 & 0,41 & 1,69 & 0,05 & 0,68 & 3,08 & 0,06 & 1,06 & 4,41 & 0,22 \\
\hline Total & 100,0 & 100,0 & 100,0 & 100,0 & 100,0 & 100,0 & 100,0 & 100,0 & 100,0 & 100,0 & 100,0 & 100,0 & 100,0 & 100,0 & 100,0 & 100,0 & 100,0 & 100,0 \\
\hline
\end{tabular}

${ }^{1 /} \mathrm{PD}$ (plantio direto); AA (arado de aivecas); AD (arado de discos); GA (grade aradora).

${ }^{2}$ Inclui as espécies Digitaria horizontalis e Digitaria insularis. 
Tabela 3 - Importância relativa (\%) das espécies de plantas daninhas presentes na cultura do feijão, em função dos diferentes sistemas de preparo do solo. Coimbra/MG, 2001

\begin{tabular}{|c|c|c|c|c|c|c|}
\hline \multirow{2}{*}{ Espécie } & \multicolumn{6}{|c|}{ Sistema de preparo do solo ${ }^{\frac{1}{}}$} \\
\hline & PD & $\mathrm{AD}$ & AA & GA & $\mathrm{GA}+\mathrm{AD}$ & $\mathrm{GA}+\mathrm{AA}$ \\
\hline Bidens pilosa & 12,17 & 9,39 & 7,87 & 7,59 & 6,10 & 7,38 \\
\hline Artemisia verlotorum & 0,96 & 3,64 & 7,69 & 2,59 & 1,67 & 3,17 \\
\hline Galinsoga parviflora & 33,93 & 13,27 & 9,45 & 16,31 & 7,00 & 5,46 \\
\hline Digitaria sp. $^{2^{\prime}}$ & 5,13 & 3,39 & 4,84 & 3,21 & 4,85 & 4,12 \\
\hline Brachiaria plantaginea & 6,73 & 15,14 & 17,20 & 17,53 & 32,78 & 24,28 \\
\hline Zea mays & 16,42 & 10,47 & 7,06 & 10,39 & 4,05 & 4,26 \\
\hline Cyperus rotundus & 0,99 & 26,60 & 34,77 & 22,63 & 29,67 & 34,85 \\
\hline Ipomoea grandifolia & 4,15 & 2,50 & 2,71 & 2,49 & 2,77 & 2,73 \\
\hline Solanum americanum & 5,85 & 13,31 & 3,30 & 14,68 & 4,59 & 8,06 \\
\hline Richardia brasiliensis & 4,00 & 0,00 & 1,63 & 0,72 & 1,27 & 1,90 \\
\hline Outros & 9,66 & 2,29 & 3,49 & 1,86 & 5,25 & 3,79 \\
\hline
\end{tabular}

${ }^{1 /} \mathrm{PD}$ (plantio direto); AA (arado de aivecas); AD (arado de discos); GA (grade aradora).

${ }^{2}$ Inclui as espécies Digitaria horizontalis e Digitaria insularis.

O tamanho das sementes é uma característica importante na emergência de plântulas e no estabelecimento das espécies em áreas sujeitas ao preparo periódico do solo, principalmente quando estas não apresentam mecanismos de dormência sofisticados (Radosevich et al., 1996). Artemisia verlotorum apresentou maior IR nos sistemas com preparo convencional do solo, especialmente o AA (Tabela 3). Esse comportamento está relacionado à presença de intensa rede de rizomas dessa espécie no solo. Os implementos de preparo do solo podem beneficiar as plantas que apresentam reprodução vegetativa através da dispersão e fragmentação, que induz a quebra da dormência e brotação de partes destas plantas, aumentando a infestação (Pitelli, 2000; Jakelaitis et al., 2003). Entretanto, o aumento da intensidade de revolvimento provocou o decréscimo dos valores de DeR e DoR de A. verlotorum (Tabela 2). Esse comportamento pode estar relacionado à forma como o AA trabalha o solo. Apesar de atingir profundidades maiores, esse implemento promove melhor inversão da leiva e o efeito de esboroamento é menor do que quando se utiliza o arado de discos. Esta característica permite ao AA a inversão das camadas com reduzido distúrbio do solo, fragmentando menos a rede de rizomas e promovendo a formação de brotos mais fortes, com maior capacidade de emergência e estabelecimento.
Digitaria sp. apresentou maior IR no PD (Tabela 3), devido, principalmente, ao aumento da DeR das espécies do gênero (Tabela 2). Em relação às demais espécies, os valores de IR não foram muito elevados, principalmente em razão das baixas temperaturas do período de inverno da região (Ferreira et al., 1998). Zanin et al. (1997), Duarte \& Deuber (1999), Pasqualetto (1999) e Jakelaitis et al. (2003) verificaram que as espécies do gênero Digitaria são beneficiadas no PD. Brachiaria plantaginea, embora também possa ter sido prejudicada pelas baixas temperaturas, apresentou alta IR nos sistemas convencionais, especialmente o GA+AD e GA+AA. Nestes sistemas, o revolvimento do solo é mais intenso, distribuindo as sementes de maneira uniforme ao longo do perfil e aumentando a superficie de contato destas com o solo. Esse pode ser um fator importante, uma vez que a interação entre as sementes e os agregados do solo promove a manutenção da viabilidade do estado de dormência por mais tempo (Reuss et al., 2001). No PD, a ausência de revolvimento mecânico do solo e a manutenção da cobertura morta reduzem a germinação e a emergência da espécie (Theisen \& Vidal, 1999). O aumento desta espécie nos sistemas com preparo convencional do solo foi verificado por Pasqualetto (1999) e Pereira (2000). Embora o milho (Zea mays) não se enquadre em alguns conceitos de plantas daninhas, apresentou 
elevada IR dentro da comunidade (Tabela 3), em decorrência da grande quantidade de biomassa acumulada (Tabela 2). A presença da espécie se deve às perdas de grãos ocorridas na colheita da safra anterior. A DeR da espécie diminuiu conforme aumentaram a profundidade e a intensidade de revolvimento, obedecendo à seguinte ordem: $\mathrm{PD}>\mathrm{GA}>\mathrm{AD}>\mathrm{GA}+\mathrm{AA}>\mathrm{AA}>$ $\mathrm{GA}+\mathrm{AD}$ (Tabela 2), devido ao enterrio e à decomposição das sementes no interior do solo.

Cyperus rotundus apresentou elevada IR em todos os tratamentos com preparo convencional do solo. Esse comportamento da espécie se deve ao revolvimento do solo, cujo efeito favorece a sua propagação e seu estabelecimento, em razão da quebra de dormência pela divisão da cadeia de tubérculos e eliminação da dominância apical. No PD, a ausência de revolvimento mecânico e o efeito da cobertura morta e da dessecação reduzem a brotação dos tubérculos. Jakelaitis et al. (2003) verificou que o PD reduziu o número e a biomassa dos tubérculos e aumentou a proporção de tubérculos dormentes da espécie, o que proporcionou redução de até 94\% nas manifestações epígeas dessa espécie neste sistema.

Ipomoea grandifolia apresentou maior IR no PD. Duarte \& Deuber (1999) constataram altas infestações por plantas da família Convolvulaceae em áreas submetidas ao cultivo com pouca mobilização do solo (preparo com grade niveladora na safrinha), mas não as encontraram em áreas sob PD. Solanum americanum apresentou maior IR nos tratamentos AD e GA, onde o revolvimento do solo é mais intenso e menos profundo. Reuss et al. (2001) verificaram que a interação entre as sementes e os agregados do solo foi um fator determinante na adaptação de outra espécie da família Solanaceae (Solanum ptycanthum), em áreas submetidas ao revolvimento do solo. Entretanto, o enterrio das sementes em profundidades maiores prejudica a espécie, por causa do tamanho reduzido das sementes, que dificulta a emergência das plântulas.

A aplicação dos herbicidas em pós-emergência afetou a comunidade de plantas daninhas por meio de três mecanismos básicos: alteração da biomassa seca total e da densidade de indivíduos da comunidade (Tabela 1); ação diferenciada dos herbicidas sobre as diferentes espécies presentes, alterando a DeR; e diminuição da competição após a aplicação, favorecendo o acúmulo de biomassa DoR naquelas que escaparam do controle (Tabela 4). Embora os sistemas de preparo não tenham apresentado diferenças significativas entre si, as diferenças numéricas devido à aplicação dos herbicidas em pós-emergência influenciam a IR das espécies, uma vez que participam dos cálculos dos índices de DeR, FR e DoR. Isso ficou evidente no tratamento $\mathrm{PD}$, onde a comunidade apresentou biomassa seca e densidade de indivíduos muito baixa após a aplicação, imprimindo grande IR às poucas plantas que se mantiveram viáveis, como foi o caso de Galinsoga parviflora, que apresentou grande importância dentro da diminuta comunidade, devido apenas a algumas plantas que escaparam do controle (Tabela 5).

A aplicação da mistura herbicida promoveu controle total de algumas espécies da área, como Digitaria sp. e Zea mays (Tabelas 4 e 5). Bidens pilosa, Artemisia verlotorum e Brachiaria plantaginea foram controladas apenas no PD. Nos tratamentos com preparo convencional do solo, Brachiaria plantaginea apresentou redução de todos os seus índices, principalmente a DoR; Artemisia verlotorum apresentou aumento da DoR, principalmente no AA; e Cyperus rotundus aumentou todos os seus indices, exceto a DeR no AA. No PD, Richardia brasiliensis apresentou aumento de todos os seus indices. Essas diferenças alteraram as importâncias relativas (IR) das espécies nos diferentes sistemas de preparo (Tabela 5).

As espécies que aumentaram a IR dentro da comunidade devido à aplicação do herbicida foram Galinsoga parviflora, Cyperus rotundus e Richardia brasiliensis. Artemisia verlotorum aumentou a IR principalmente no preparo do solo com AA. Apesar de ter sido prejudicada pelas temperaturas baixas no período, Cyperus rotundus apresentou elevada IR em todos os tratamentos convencionais, beneficiada pela diminuição da competição, principalmente com as gramineas, que foram controladas pelos herbicidas. Esses resultados se assemelham aos obtidos por Jakelaitis et al. (2003), que constatou aumento expressivo da IR de C. rotundus na comunidade após a aplicação do herbicida em pós-emergência, inclusive em PD.

A população de plantas daninhas presente após a aplicação dos herbicidas teve 
Tabela 4 - Índices fitossociológicos (\%) de densidade (DeR), freqüência (FR) e dominância (DoR) das plantas daninhas presentes na cultura do feijão, em função dos diferentes sistemas de preparo do solo, com aplicação de herbicida em pósemergência ${ }^{1 /}$. Coimbra-MG, novembro de 2001

\begin{tabular}{|c|c|c|c|c|c|c|c|c|c|c|c|c|c|c|c|c|c|c|}
\hline \multirow{3}{*}{ Espécie } & \multicolumn{18}{|c|}{ Sistema de preparo do solo ${ }^{2 /}$} \\
\hline & \multicolumn{3}{|c|}{$\mathrm{PD}$} & \multicolumn{3}{|c|}{$\mathrm{AD}$} & \multicolumn{3}{|c|}{$\mathrm{AA}$} & \multicolumn{3}{|c|}{$\mathrm{GA}$} & \multicolumn{3}{|c|}{$\mathrm{GA}+\mathrm{AD}$} & \multicolumn{3}{|c|}{$\mathrm{GA}+\mathrm{AA}$} \\
\hline & DeR & FR & DoR & DeR & FR & DoR & DeR & FR & DoR & DeR & FR & DoR & DeR & FR & DoR & DeR & \begin{tabular}{|l|} 
FR \\
\end{tabular} & DoR \\
\hline Bidens pilosa & 0,00 & 0,00 & 0,00 & 0,67 & 12,50 & 3,21 & 0,67 & 6,12 & 6,62 & 0,26 & 7,89 & 0,12 & 0,27 & 9,52 & 0,29 & 0,21 & 6,67 & 0,17 \\
\hline Galinsoga parviflora & 72,22 & 41,67 & 86,24 & 1,51 & 8,33 & 3,67 & 0,00 & 2,04 & 0,00 & 0,72 & 13,16 & 0,74 & 0,87 & 4,76 & 3,56 & 0,41 & 6,67 & 0,95 \\
\hline Artemisia verlotorum & 0,00 & 0,00 & 0,00 & 1,29 & 12,50 & 2,68 & 10,50 & 16,33 & 21,02 & 0,46 & 7,89 & 1,45 & 0,20 & 4,76 & 3,27 & 1,51 & 16,67 & 1,43 \\
\hline Brachiaria plantaginea & 0,00 & 0,00 & 0,00 & 0,28 & 6,25 & 11,35 & 2,29 & 8,16 & 4,89 & 0,26 & 7,89 & 1,28 & 0,80 & 11,90 & 7,97 & 0,27 & 6,67 & 0,68 \\
\hline Chamaesyce hipossifolia & 5,56 & 8,33 & 0,53 & 0,11 & 8,33 & 0,36 & 0,13 & 2,04 & 0,10 & 0,07 & 2,63 & 0,02 & 0,07 & 2,38 & 0,06 & 0,07 & 3,33 & 0,01 \\
\hline Cyperus rotundus & 0,00 & 0,00 & 0,00 & 94,73 & 14,58 & 76,76 & 73,08 & 14,29 & 53,07 & 95,69 & 21,05 & 87,43 & 92,31 & 14,29 & 76,36 & 95,07 & 20,00 & 93,83 \\
\hline Cyperus esculentus & 0,00 & 0,00 & 0,00 & 0,39 & 4,17 & 0,80 & 9,29 & 4,08 & 7,99 & 0,72 & 2,63 & 1,08 & 0,33 & 2,38 & 0,27 & 1,71 & 6,67 & 2,40 \\
\hline Commelina benghalensis & 5,56 & 8,33 & 9,31 & 0,11 & 2,08 & 0,19 & 0,81 & 6,12 & 0,29 & 0,13 & 2,63 & 0,09 & 0,00 & 0,00 & 0,00 & 0,00 & 0,00 & 0,00 \\
\hline Ipomoea grandifolia & 5,56 & 8,33 & 0,95 & 0,28 & 10,42 & 0,44 & 0,27 & 6,12 & 0,81 & 0,39 & 7,89 & 0,74 & 0,80 & 14,29 & 0,78 & 0,14 & 6,67 & 0,09 \\
\hline Richardia brasiliensis & 11,11 & 25,00 & 2,96 & 0,22 & 6,25 & 0,30 & 2,42 & 10,20 & 2,00 & 0,52 & 5,26 & 0,28 & 0,47 & 9,52 & 0,35 & 0,62 & 16,67 & 0,44 \\
\hline
\end{tabular}

1/ fluazifop-p-butil + fomesafen $\left(160+200 \mathrm{~g} \mathrm{ha}^{-1}\right)$, aplicados 32 dias após a semeadura (DAS).

2/ PD (plantio direto); AA (arado de aivecas); AD (arado de discos); GA (grade aradora).

Tabela 5 - Importância relativa (\%) das plantas daninhas presentes na cultura do feijão, em função dos diferentes sistemas de preparo do solo, com aplicação de herbicidas ${ }^{\underline{1} /}$ em pós-emergência. Coimbra-MG, novembro de 2001

\begin{tabular}{|c|c|c|c|c|c|c|}
\hline \multirow{2}{*}{ Espécie } & \multicolumn{6}{|c|}{ Sistema de preparo do $\operatorname{solo}^{2 /}$} \\
\hline & $\mathrm{PD}$ & $\mathrm{AD}$ & AA & GA & $\mathrm{GA}+\mathrm{AD}$ & $\mathrm{GA}+\mathrm{AA}$ \\
\hline Bidens pilosa & 0,00 & 5,46 & 4,47 & 2,76 & 3,36 & 2,35 \\
\hline Galinsoga parviflora & 66,71 & 4,50 & 0,68 & 4,87 & 3,06 & 2,67 \\
\hline Artemisia verlotorum & 0,00 & 5,49 & 15,95 & 3,27 & 2,75 & 6,54 \\
\hline Brachiaria plantaginea & 0,00 & 5,96 & 5,11 & 3,14 & 6,89 & 2,54 \\
\hline Chamaesyce hipossifolia & 4,81 & 2,94 & 0,76 & 0,90 & 0,83 & 1,14 \\
\hline Cyperus rotundus & 0,00 & 62,03 & 46,81 & 68,06 & 60,99 & 69,63 \\
\hline Cyperus esculentus & 0,00 & 1,79 & 7,12 & 1,48 & 1,00 & 3,59 \\
\hline Commelina benghalensis & 7,73 & 0,80 & 2,41 & 0,95 & 0,00 & 0,00 \\
\hline Ipomoea grandifolia & 4,95 & 3,71 & 2,40 & 3,01 & 5,29 & 2,30 \\
\hline Richardia brasiliensis & 13,02 & 2,26 & 4,87 & 2,02 & 3,45 & 5,91 \\
\hline Outros & 2,78 & 5,07 & 9,42 & 9,54 & 12,39 & 3,33 \\
\hline
\end{tabular}

1/ fluazifop-p-butil + fomesafen $\left(160+200 \mathrm{ha}^{-1}\right)$, aplicados 32 dias após a semeadura (DAS).

${ }^{2} \mathrm{PD}$ (plantio direto); AA (arado de aivecas); AD (arado de disco); GA (grade aradora).

importante participação de espécies que apresentam tolerância a estes, além de algumas espécies suscetiveis que escaparam do controle (devido ao "efeito guarda-chuva", por exemplo). Apesar de estas espécies apresentarem baixa DeR e FR (Tabela 4), elas tiveram participação expressiva na formação da biomassa da comunidade (DoR). Segundo Zanin et al. (1997), estas plantas podem adquirir importância à medida que suas presenças deixam de ser promovidas por simples flutuações populacionais e tendem a estabelecer-se definitivamente nos sistemas.

\section{LITERATURA CITADA}

ABDIN, O. A. et al. Cover crops and interrow tillage for weed control in short season maize (Zea mays). Eur. J. Agron., v. 12, p. 93-102, 2000.

DUARTE, A. P.; DEUBER, R. Levantamento de plantas infestantes em lavouras de milho "safrinha" no Estado de São Paulo. Planta Daninha, v. 17, p. 297-307, 1999.

FERREIRA, F. A. et al. Manejo de plantas daninhas. In: VIEIRA, C.; PAULA Jr., T. J.; BORÉM, A. (Eds.) Feijão: aspectos gerais e cultura no Estado de Minas. Viçosa: Universidade Federal de Viçosa, 1998. p. 99-123.

Planta Daninha, Viçosa-MG, v. 23, n. 1, p. 17-24, 2005 
GHERSA, C. M. et al. Advances in weed management strategies. Field Crops Res., v. 67, p. 95-104, 2000.

JAKELAITIS, A. et al. Dinâmica populacional de plantas daninhas sob diferentes sistemas de manejo nas culturas de milho e feijão. Planta Daninha, v. 21, n. 1, p. 71-79, 2003.

PASQUALETTO, A. Sucessão de culturas como alternativa de produção em plantio direto no Cerrado. 1999. 135 f. Tese (Doutorado em Fitotecnia) - Universidade Federal de Viçosa, Viçosa, 1999.

PEREIRA, E. S. et al. Avaliações qualitativas e quantitativas de plantas daninhas na cultura da soja submetida aos sistemas de plantio direto e convencional. Planta Daninha, v. 18, p. 207-217, 2000.
PITELLI, R. A. Estudos fitossociológicos em comunidades infestantes de agroecossistemas. J. Conserb., v. 1, n. 2, p. 1-7, 2000.

RADOSEVICH, S.; HOLT, J.; GHERSA, C. Weed ecology: implication for management. 2.ed. New York: John Wiley \& Sons, 1996. 573 p.

REUSS, S. A.; BUHLER, D. D.; GUNSOLUS, J. L. Effects of soil depth and aggregate size on weed seed distribution and viability in a silt loam soil. Appl. Soil Ecol., v. 16, p. 209$217,2001$.

THEISEN, G.; VIDAL, R. A. Efeito da cobertura do solo com resíduos de aveia preta nas etapas do ciclo de vida do capimmarmelada. Planta Daninha, v. 17, p. 189-196, 1999.

ZANIN, G. et al. Ecological interpretation of weed flora dynamics under different tillage systems. Agric. Ecosy. Environ., v. 66, p. 177-188, 1997. 